\title{
Desencuentros culturales en la novela Columpio al aire del escritor Lisandro Chávez Alfaro
}

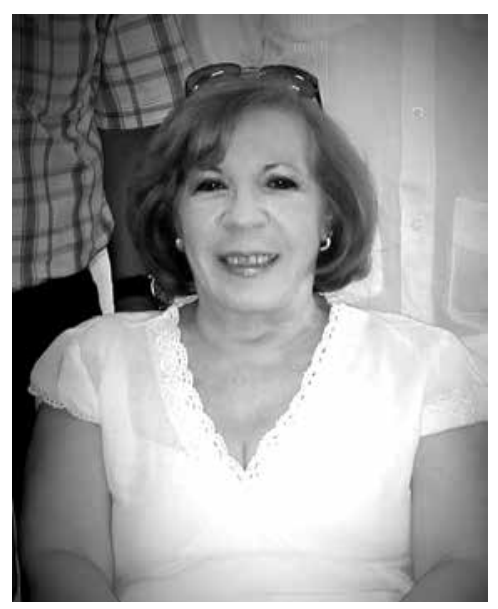

Isolda Rodríguez Rosales'

Este homenaje al Maestro

\section{Resumen}

T a novela Columpio al Aire, define y delimita los territorios culturales del Caribe Nicaragüense. Identifica Ly denuncia la intervención de los invasores al intentar conculcar los valores patrimoniales de la Nación, y centro de la historia narrada con abordaje de exclusión y manifiestos abusos culturales. La religión, la libertad de enseñanza en lengua madre, recuperar las tradiciones, lanzadas por el invasor a la pendiente de la disolución, son las expectativas del resurgimiento de los valores.

\section{Desarrollo}

Columpio al aire, última novela que publicara el admirable escritor Chávez Alfaro, aborda lo que llamamos los desencuentros culturales que se originaron en Bluefields después de la irrupción del liberalismo en el sector de la costa Caribe. Lo que la historiografía oficial ha dado en llamar la "Reincorporación de la Mosquitia" (1894), hecho que se realiza con el pretexto de unificar la Nación, aunque ello signifique el irrespeto a las minorías étnicas.

El narrador reconstruye, mediante abundantes saltos temporales o anacronías, la historia del Caribe, y toma para ello las historias orales o rememoraciones que guardan, como parte de su tradición, los descendientes de los reyes mískitus. Desde una perspectiva extradiegético, el narrador cuenta cómo cambió la vida de los habitantes de la región, a partir de la llegada de lo que él llama "los invasores". El irrespeto por sus costumbres, el culto a los ancestros, propio de su cultura, constituyen el tema primordial de la historia.

\footnotetext{
Nicaragüense, nacida en Estelí. Narradora, ensayista, historiadora y poeta. Graduada en Letras y dedicada al quehacer literario durante toda su vida, como catedrática universitaria. Realizó Cursos Monográficos de Doctorado en Filología Española (Málaga-Madrid) y posgrados en Literatura Española Contemporánea y Semiótica Literaria. Catedrática universitaria en la UCA y UNAN. Mujer polifacética, sus publicaciones abarcan áreas bien definidas: Crítica literaria: Una década en la narrativa nicaragüense y otro ensayos. Managua: CNE, 1999. En el país de las alegorías: CNE, 2005, "Rasgos poéticos de la primera poesía albertiana" publicado parcialmente en la Revista El pez y la serpiente. Tiene inédito el ensayo monográfico: "Lizandro Chávez y sus deudas con la historia". Miembro de Número de la Academia Nicaragüense de la Lengua y correspondiente de la Real Academia Española de la Lengua. Miembro correspondiente de la Academia de Geografía e Historia de Nicaragua. Participa en congresos, simposios y eventos culturales dentro y fuera del país. En 2008 recibió la Orden Independencia Cultural “Rubén Darío" por sus aportes a la literatura y cultura nacional. E-mail: isoldarr@yahoo.com
} 
La respuesta de los bluefileños ante la ocupación de gente del pacífico, (gobierno liberal) fue organizar un coro con voces de feligreses moravos y que interpretarán "El Mesías" de Haendel, para la Pascua de Navidad. Esto forma parte de la necesidad de conservar los valores, las tradiciones propias de su cultura. El reverendo moravo Fassbinder manifiesta que lo más importante son los valores: "la religión, la libertad de enseñanza en lengua madre; recuperar las tradiciones, lanzadas por el invasor a la pendiente de la disolución" (Chávez Alfaro, 1999: 43).

La historia del relato inicia cuando Viola Hendy acompañada de su sobrina Tisí, atraviesan la calle del Rey hasta llegar al cementerio donde descansaban su ancestros, para depositar flores en sus tumbas, rebelde ante la orden emitida por el General Migloria, decretaba el traslado de los restos a un nuevo panteón. Se llegó a decir que quien no exhumara los huesos de sus deudos, vería convertirse los restos en pólvora.

El lector asiste a un desencuentro cultural originado por el deseo de los liberales de imponer una cultura ajena a la local, pero que ellos creen superior. Se trata del hecho repetido a través de los tiempos, cuando la cultura dominante o grupo con mayor poder social, impone su cultura a los demás, por considerar las otras como inferiores.

Bluefields contaba con un sistema educativo bien organizado, dirigido por los religiosos moravos, los mejores maestros provenían de Jamaica y los libros de texto, de Inglaterra. Estudiaban historia, literatura, poesía, gramática, entre otros temas, todo en lengua inglesa, que habían aprendido en los tiempos que el territorio fue protectorado británico.

El cierre de los colegios fundados por los moravos queda plasmado en la novela Columpio al aire, cuando el narrador señala: “...diez iglesias escuelas establecidas durante medio siglo de trabajo en toda la extensión de lo que había sido el Reino Mískitu, estaban amenazadas de clausura por efecto de la anexión". (Ibíd., 98) El cierre de sus centros educativos amenazaba seriamente la pérdida de su identidad y cultura; por eso, para preservarla, planifican la apertura de escuelas clandestinas, que funcionarán en casas particulares donde las mujeres podrán transmitirles su cultura y conocimientos, su lengua y religión: "Con una ilegal escuela privada acogida en su propia casa, quería Zemelia contrarrestar la clausura de las escuelas moravas; mantener vivo su propio modo de ver, conocer y entender" (Ibíd,.98).

Otro desencuentro se da por el tema religioso. La población de Bluefields, en esos años era en su mayoría morava y poseedora de una gran cultura musical. La preparación del coro para interpretar "El Mesías", genera una enorme polémica que deviene en el enfrentamiento de dos culturas diversas. El narrador no oculta su desagrado al plasmar con ironía el desconocimiento que la gente del Pacífico tenía de esa magistral pieza musical:

Gerardo Chumbulún levantó el cabo de tabaco entre sus dedos teñidos de maque. Envuelta en humo dejó caer la última noticia sobre los preparativos para aquel extraño canto religioso apodado El Mesías... hubo quien jurara que era una representación teatral, salpicada de danzas, con coros recitados "en africano" y en griego bíblico. (Ibíd.: 58-59).

La respuesta a la iniciativa de los moravos proviene de un hojalatero, y consiste en celebrar la fiesta de San Jerónimo, y no por devoción, sino como medio de combatir la cultura morava. Se revela una actitud intransigente hacia la cultura local; hay que imponer la del Pacífico, española, cristiana, contra la inglesa y protestante. El narrador resalta la actitud de menosprecio y racismo que demostró la gente del Pacífico. Cuando se oficializa la petición para la fiesta, Medrano le dice a Migloria: “... queremos hacerles sus fiestas a San Jerónimo aquí en Brufil. Que sepan estos negros quiénes somos (Ibíd. 88). En este pequeño diálogo está plasmado la visión de los "invasores" hacia la población caribeña, se trata de imponer a toda costa, una tradición desconocida en la región.

El narrador plantea en su discurso narratológico un juego de oposiciones: blanco-negro; PacíficoCaribe; católico-protestante, en un fuerte contraste. Unas relaciones tensas en un contrapunto que denota el deseo de imponer, de unos y preservar de otros. Tradiciones versus modernidad. Educación versus ignorancia. Sin que ninguna de las partes en conflicto, demuestre interés por conocer, comprender la cultura del "otro".

Pero nada es blanco o negro. Antes que la religión morava, los caribeños profesaron cultos de origen africano, llevados por sus antepasados, en 
los que predomina el culto a los ancestros. Por ello es que Viola Hendy no permite que las tumbas de sus ancestros sean profanadas, y pide al general Migloria "desconfiscar las tumbas de los reyes", a lo que el hombre responde: "En esta República no hay reyes., señora". (Ibíd. 162) en una pugna por mantener su decisión de construir casas sobre el cementerio donde descansan los reyes mískitus. En un acto completamente irreverente el teniente Sanarrusia pretende construir su casa "sobre las podridas tumbas de ese adefesio que fue el reino mískitu". Esta actitud tiene una connotación muy fuerte, en tanto lo que desea es destruir los símbolos, lo más sagrado para el pueblo. Con ello, logrará derrumbar sus creencias, su cultura y su mundo.

Todo este planteamiento revela la voz del narrador en abierta protesta por la forma en que se ha visto y menospreciado la cultura del "otro". Viola Hendy se alza como la voz de los vencidos, que protesta por la irrupción de una cultura que no es la suya ni la de sus antepasados. El general Migloria es la voz de los vencedores, los que cuentan la historia, los que allanan y atropellan, sin respeto por las tradiciones. Los dos oponentes, como los clasificaría Greimas: el bien y el mal en su eterna danza a través del tiempo.

Chávez Alfaro decodifica la historiografía nacional y la recrea desde la visión caribeña, su objetivo es reivindicar a un pueblo que "cuando Nicaragua se proclamaba república, el Reino Mískitu ya tenía ciento ochenta años de existencia. Cuando Nicaragua se desgarraba por arrojar a los filibusteros, en 1855 el Rey George Augustus Frederic ya estaba integrando el primer Concejo de Estado en Bluefields" (Columpio, 44) El discurso narratológico tiene una base histórica concreta que es recreada por el autor con un acertado manejo estilístico. La novela refleja la tensión creada por un grupo cultural que irrumpe en otro, para imponer su propia cultura, por considerarla superior y legítima. La historiografía nacional, como suele suceder, deslegitimó la cultura caribeña, como medio de justificar el irrespeto y atropellos que se han cometido.

Con esta novela Lisandro Chávez Alfaro vuelve a su raíz nutricia y devela una sociedad signada por la herencia de Juan Amos Comenio que preconizó la enseñanza como medio de vida. Ese pueblo que canta himnos moravos, pero que guarda con celo la tumba de sus ancestros, consulta al sukia y se estremece con el ritmo caribeño, con perfumes a Ilang-ilang.

Columpio al aire se constituye en ventana hacia esta cultura, tan cercana y lejana a nosotros, ofrece la riqueza de las tradiciones, comidas, cantos y poesía que se eleva en las voces de las niñas moravas, elevándose "como una catedral sonora en las costas de la bahía de Bluefields". Voces que trascienden los pantanos y suben hasta los cielos llenos de "estrellas invisibles al sol". Es una bandera que se levanta y dice que la princesa Selesia, aún vive, Ocelin y Tisí aún cantan. Columpio que se mece entre la vegetación cada día más devastada, columpio que se mueve en el tiempo y que nos trae el imponente coro de Haendel que aún resuena en nuestros oídos.

Managua, Octubre 1999, Enero 2000.

\section{Referencia bibliográfica}

Chávez Alfaro. Columpio al aire, Managua: ediciones UCA, 1999 